\title{
As Universidades Brasileiras e os 40 anos da Pós-graduação da EEFE-USP
}

http://dx.doi.org/10.11606/1807-55092017000nesp051

A história da pós-graduação no Brasil tem sua origem a partir do modelo de cátedras, instituído em 1930 por algumas Universidades Brasileiras e amparado por pesquisadores refugiados da guerra de países europeus. Posteriormente, uma das primeiras tentativas de melhor definir as açôes e institucionalizar a pós-graduação foi feita com a criação da CAPES, em 1951, pelo Decreto 29.741 que tinha por objetivo "assegurar a existência de pessoal especializado em quantidade e qualidade suficientes para atender às necessidades dos empreendimentos públicos e privados que visam ao desenvolvimento do país”. Em 1965, e em decorrência dos processos de regulamentação, foram criados os primeiros 38 cursos de pós-graduação (27 mestrados e 38 doutorados).

$\mathrm{Na}$ área da Educação Física, a pós-graduação teve seus primeiros cursos instituídos entre a segunda metade da década de 1970 e início da década de 1980 e pode ser considerada como relativamente jovem, especialmente se comparada a áreas mais tradicionais e altamente consolidadas. Os esforços para a abertura desses cursos decorreram do empenho e de açóes governamentais para qualificar mestres e doutores, predominantemente nos Estados Unidos. Destes esforços derivaram os primeiros programas de pós-graduação na área de Educação Física. A Escola de Educação Física da Universidade teve seu início em março de 1977 e foi uma das pioneiras na criaçáo de um curso de mestrado e em 1989 o primeiro doutorado na América Latina.

Atualmente, o Programa de Pós-graduação da Escola de Educaçáo Física da Universidade de São Paulo, especialmente ao longo dos últimos 10 anos tem desempenhado um papel de liderança importante na área, o que tem propiciado excelentes avaliaçóes em seu desempenho e de destaque entre as melhoras notas na área. A excelência do programa da Universidade de São Paulo pode ser expressa por meio de vários indicadores que pode ser sintetizada pelo fato de deter a única nota 7 na Área 21 e na subárea da Educação Física. Além disso, o programa tem desempenhado importante papel no

\section{André Luiz Felix RODACKI*}

enfrentamento dos desafios da área e contribuído com reflexôes e críticas que visam aprimorar o processo de consolidaçấo da área.

Vários indicadores demonstram o elevado desempenho do programa da Universidade de Sáo Paulo, que tem se alinhado com as políticas estabelecidas no Plano Nacional de Pós-graduação e formado mais doutores do que mestres, o que demonstra sua vocaçáo para a formação de recursos humanos de alto nível. A proporção de dissertaçóes em relação as teses foi de 0,81 , ou seja, houve 293 teses $(55,2 \%)$ e 238 (44,8\%) dissertações defendidas dentre as 531 defesas ocorridas entre 2013 e 2016. Tais indicadores são comparáveis com programas consolidados de outras áreas do conhecimento que primam pela formação de doutores. Quando se observa o número de orientadores que atuam no programa, a média ao longo do quadriênio é de 2,15 defesas de doutorado e 1,75 defesas de mestrado.

O programa é um dos maiores do país e contou com aproximadamente 34 docentes em 2016, que náo se qualifica apenas pela sua diversidade de atuação em duas áreas de concentração (Estudos Biodinâmicos; Sócio-Culturais e Comportamentais) que têm como foco a Educaçáo Física e o Esporte. $\mathrm{O}$ corpo docente é altamente qualificado e conta com um expressivo número de 18 bolsistas produtividade, que correspondem a aproximadamente $45 \%$ do volume de docentes (seis pesquisadores 2 e nove pesquisadores 1). A elevada qualidade do corpo docente vinculado ao programa permitiu que a USP obtivesse a $22^{a}$ posição no "ranking" mundial "Shanghai Ranking's" para Departamentos e Escolas de Ciências do Esporte em 2016, sendo a melhor classificada entre as instituições brasileiras e sulamericanas. A produção intelectual do programa de Educação Física e Esporte chama atenção, visto que no triênio anterior (2010-2012) respondeu sozinha por $9,3 \%$ de toda a Área 21 . As publicações do programa no estrato A1 corresponderam a $20,7 \%$ da área entre 2010-2012 e 13,3\% entre 2012-2014. A FIGURA 1 demonstra a distribuição entre os principais programas mais produtivos da Área e
* Setor de Ciências

B i o I ó g i c a s.

Universidade Federal

do Paraná, Curitiba,

PR, Brasil. 
destaca os principais programas da Educação Física. A FIGURA 2 apresenta o volume de publicaçōes no estrato A1 entre 2013-2014, identificado durante o Seminário de acompanhamento da CAPES. É necessário enfatizar que a análise da produção intelectual determinada o Seminário de Acompanhamento reflete apenas dois anos do quadriênio. Nos dados atuais do período quadrienal (depurados em maio/2017), mais uma vez indicam o impacto da instituição no cenário da área. A FIGURA 3 indica notória contribuição de artigos no estrato A1, que corresponde a aproximadamente 2,3 vezes aos valores identificados na área. Isso revela que o programa congrega um conjunto de pesquisadores de altíssima produtividade e que refletem a excelência nacional na área. A considerar que os periódicos nos estratos A1 e A2 detém fatores de impacto (JCR) e são predominantemente internacionais, pode-se identificar uma excelente penetraçáo no contexto mundial. De fato, as citaçóes recebidas nos artigos publicados ("cites per doc") são os mais elevados da Área 21.

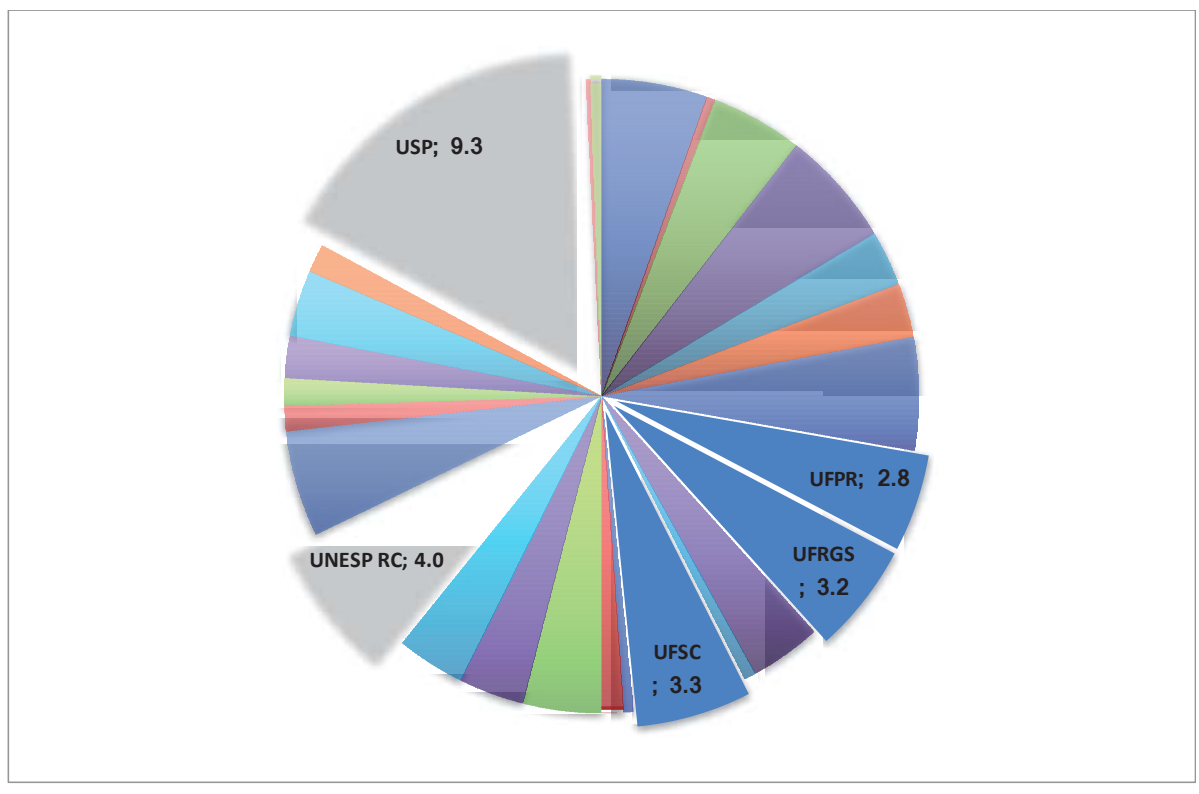

FIGURA 1 - Contribuição percentual absoluta do Programa de Educação Física e Esporte da USP na Área 21 no período de 2010-2013.

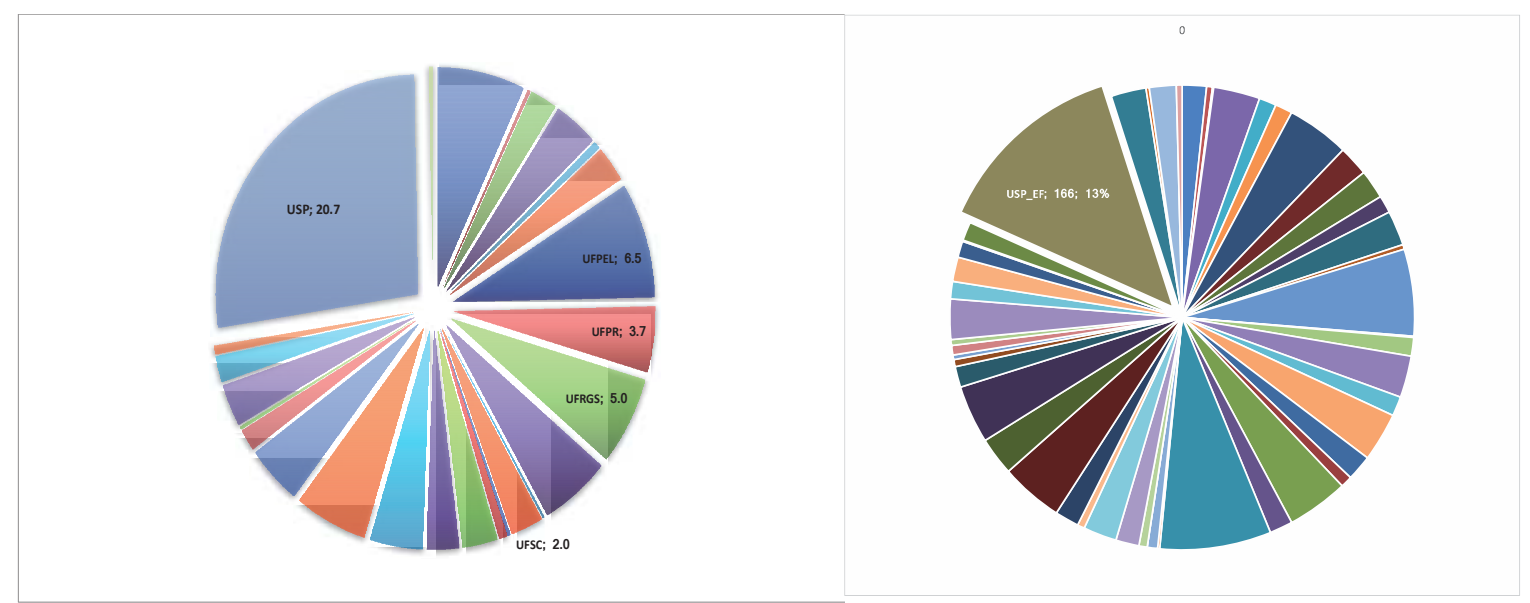

FIGURA 2 - Contribuição da produção intelectual absoluta no estrato “A1” do Programa de Pós-Graduação em Educação Física e Esporte da USP no contexto da Área 21 no interstício 2010-2012 (Painel Esquerdo) e entre o interstício 2013-2014 (Painel Direito). 


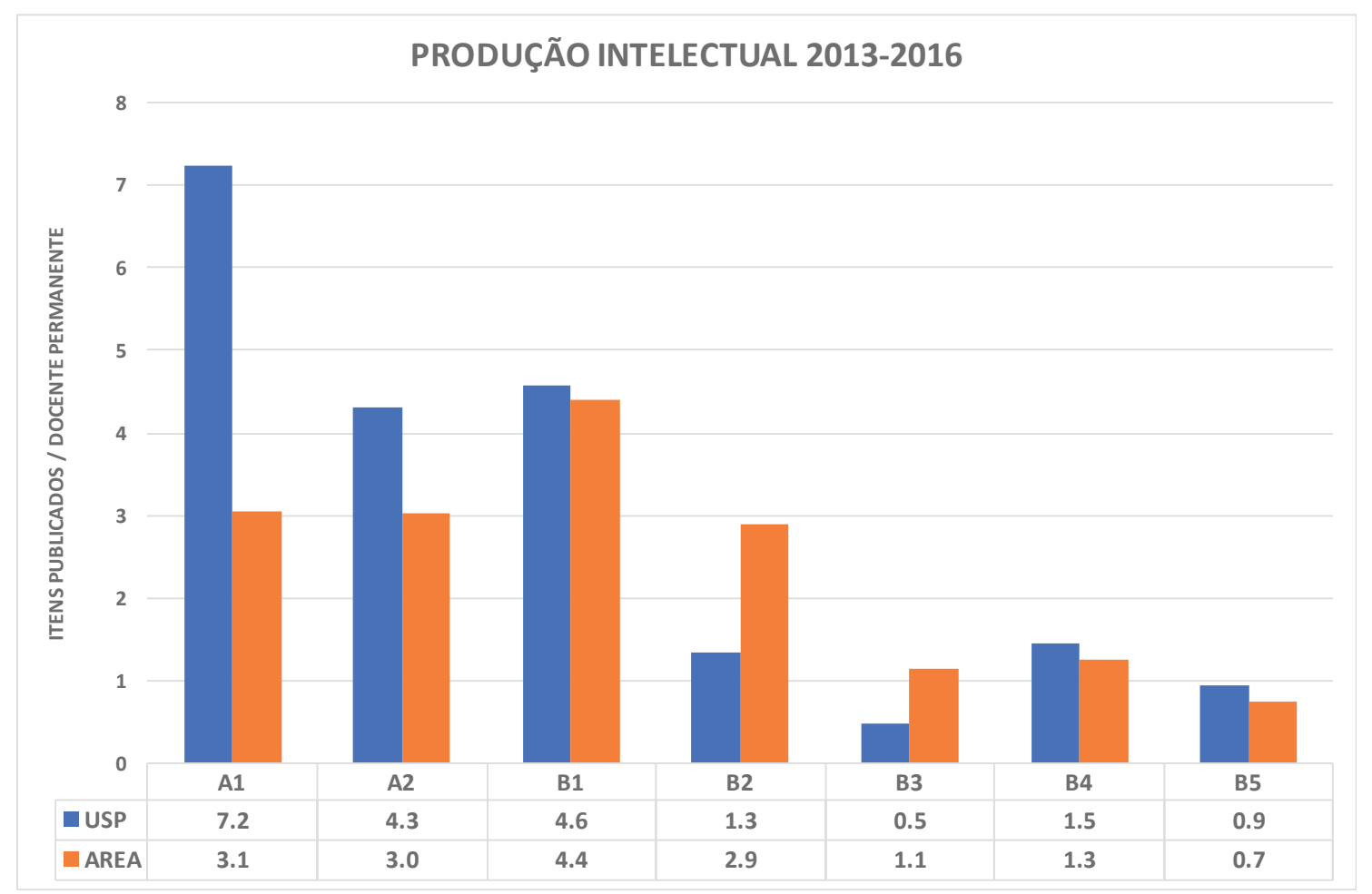

FIGURA 3 - Produção intelectual em periódicos por docente permanente ao longo de 2013-2016 da Área e do Programa de Educação Física e Esporte da USP.

O Programa de Educaçáo Física da Universidade de São Paulo não constitui apenas um centro gerador de conhecimento de excelência, mas também tem mostrado um expressivo potencial de nucleação de outros programas no país. A Nucleação de dois programas na própria Instituição, como é o caso da USP/EACH e da USP/Ribeirão Preto e de iniciativas Minter/Dinter realizadas, demonstram a força do programa. Além disso, são frequentes os programas em funcionamento da área que contam com pelo menos um egresso da USP. Talvez, os egressos seja o maior legado da instituição, visto que os pesquisadores formados da Escola de Educação Física têm sido amplamente absorvidos em vários cursos de graduação e pós-graduação em Educação Física e em outras áreas afins. Uma análise do quadro de pesquisadores do CNPq revela que aproximadamente $30 \%$ dos bolsistas são egressos de Mestrado e/ou Doutorado do curso de pós-graduação da USP. Logo, as Universidades Brasileiras têm obtido ótimos frutos do Programa de Pós-graduação da Universidade de São Paulo, o que é inconteste para o desenvolvimento qualificado e expansão da área. Tais frutos não se limitam apenas à pós-graduaçáo e seus produtos mais diretos e mais facilmente observáveis, mas também se estendem a contribuiçóes em Sociedades Científicas, Fundaçóes de Amparo à Pesquisa, Agências de Financiamento, Conselhos de Classe, Editorias de Revistas, Organização de Eventos, Representaçáo de Área na CAPES em várias outras açôes que denotam o forte perfil técnico e científico dos pesquisadores que atuam no programa e de seus egressos. Não se pode deixar de destacar a contribuiçâao da Revista Brasileira de Educação Física e Esporte (RBEFE) que consiste em um dos mais importantes veículos de divulgação do conhecimento. A RBEFE publicou 271 artigos que derivam de 41 programas de pós-graduação de 17 áreas do conhecimento. Esses números expressam a relevância da RBEFE para a área e mais uma vez reforçam seu papel de liderança na área de Educaçâo Física no país.

Uma outra característica altamente positiva é o elevado nível de internacionalização que o programa atinge perante Pesquisadores, Centros de Pesquisa e Universidades de referência de outros países. Ao longo do quadriênio vigente, observa se que aproximadamente $1 / 4$ do corpo docente realizou estágio pós-doutoral no exterior. O programa recebeu aproximadamente 30 pesquisadores de renome internacional e mais de 40 alunos realizaram estágios sanduiche em outros países. As iniciativas 
de dupla titulação que se iniciam acenam para um futuro promissor nas ações continuadas do programa no caminho da internacionalização. Esses indicadores revelam o forte viés de crescimento e excelência do programa que passa a dar visibilidade à ciência brasileira no contexto mundial.
O papel de liderança do Programa de Pósgraduação em Educação Física e Esporte da USP tem sido reconhecido por todos os pesquisadores da área que a identificam como o principal protagonista na formação de recursos humanos e produção do conhecimento na área de Educação Física. 